\title{
Increased firing frequency of spontaneous action potentials in cerebellar Purkinje neurons of $d b / d b$ mice results from altered auto-rhythmicity and diminished GABAergic tonic inhibition
}

\author{
María E. Forero-Vivas ${ }^{1}$ and Arturo Hernández-Cruz ${ }^{2}$ \\ 1 Chemistry Department, Faculty of Science, Antonio Nariño University, Bogotá, Colombia \\ 2 Department of Cognitive Neuroscience, Institute for Cell Physiology, National Autonomous University of México \\ (UNAM), Circuito exterior s/ $n$. Ciudad Universitaria, C.P. 04520, Mexico city DF, Mexico
}

\begin{abstract}
The hormone leptin, by binding to hypothalamic receptors, suppresses food intake and decreases body adiposity. Leptin receptors are also widely expressed in extra-hypothalamic areas such as hippocampus, amygdala and cerebellum, where leptin modulates synaptic transmission. Here we show that a defective leptin receptor affects the electrophysiological properties of cerebellar Purkinje neurons (PNs). PNs from $(d b / d b)$ mice recorded in cerebellar slices display a higher firing rate of spontaneous action potentials than PNs from wild type (WT) mice. Blockade of GABAergic tonic inhibition with bicuculline in WT mice changes the firing pattern from continuous, uninterrupted spiking into bursting firing, but bicuculline does not produce these alterations in $d b / d b$ neurons, suggesting that they receive a weaker GABAergic inhibitory input. Our results also show that the intrinsic firing properties (auto-rhythmicity) of WT and $d b / d b$ PNs are different. Tonic firing of PNs, the only efferent drive from the cerebellar cortex, is a persistent signal to downstream cerebellar targets. The significance of leptin modulation of PNs spontaneous firing is not known. Also, it is not clear if the increased excitability of cerebellar PNs in $d b / d b$ mice results from hyperglycemia or from the lack of leptin signaling, since both conditions coexist in the $d b / d b$ strain.
\end{abstract}

Key words: Firing frequency - Leptin receptor - Patch clamp - Cerebellum - GABAergic inhibition

\begin{abstract}
Abbreviations: CV, coefficient of variation; IBI, inter-burst interval; ISI, inter-spike interval; LepR, leptin receptor; NMDA, N-methyl-D-aspartate; NO, nitric oxide; NPY/AGRP, neuropeptide Y-agouti-related protein; PNs, Purkinje neurons.
\end{abstract}

\section{Introduction}

The adipose tissue-derived hormone, leptin, acts via its receptor (LepR) in the brain to regulate energy balance and neuroendocrine function. Adipose tissue produces

Correspondence to: Arturo Hernández-Cruz, Departamento de Neurociencia Cognitiva, Instituto de Fisiología Celular, Universidad Nacional Autónoma de México Circuito de la Investigación Científica s/n, Ciudad Universitaria, México city, D.F. CP 04520, México

E-mail: ahernan@ifc.unam.mx the hormone leptin in approximate proportion to fat stores. In addition to acting on a number of peripheral tissues, several lines of evidence indicate that leptin can enter the central nervous system (CNS) via transport across the blood brain barrier (Schwartz 1996; Banks 2003, 2006). Lack of leptin signaling due to mutation of leptin (e.g. ob/ob mice) or the LepR (e.g. $d b / d b$ mice) in rodents and humans results in extreme obesity due to increased food intake and decreased energy expenditure (Coleman 1978; Friedman and Halaas 1998; Elmquist et al. 1999). The $d b / d b$ (diabetic) mouse is originally derived from an autosomal recessive mutation on chromosome 4 
in mice from the C57BL/KsJ strain originating from Bar Harbor, Maine. The mutation in this diabetic animal was traced to the $d b$ gene, which encodes the LepR (Srinivasan and Ramarao 2007). These mice are spontaneously hyperphagic, insulin over-secretors (which causes them to become obese), hyperglycemic, hyperinsulinemic and insulin resistant within the first month of age whereas they subsequently develop hypoinsulinemia and hyperglycemia with a peak between 3-4 months of age (Shafrir 1992). The mutant LepR (Ob-R), which is encoded by the diabetes $(d b)$ gene, was initially isolated from mouse choroid plexus (Tartaglia et al. 1995). The LepR belonging to the cytokine family of receptors has several isoforms, but only the full-length isoform generates an intracellular signal. Activated LepR triggers the stimulation of JAK2 (janus activating kinase 2) tyrosine kinase that phosphorylates the intracellular domain of the receptor to create a binding site for IRS (insulin-receptor substrate) proteins activating PI3K (phosphoinositol-3 kinase ) and the MEK/ERK (mitogen-activated protein kinase-extracellular signal-regulated kinase) signaling pathway. JAK2 kinase also activates the transcription factor STAT3 (signal transducer and activator of transcription 3 ), and the JAK/STAT pathway plays the major role in leptin signaling via the membrane receptors (Bjørbæck et al. 1997; Niswender et al. 2001; Shanley et al. 2002b; Bjørbaek and Kahn 2004).

Early studies showed that low doses of leptin, when administered directly into the brain ventricles of rodents, were effective in reducing food intake and body weight (Campfield et al. 1995; Matson et al. 2000). Many of the leptin effects in the CNS are attributable to the hypothalamus, a site of high LepR mRNA expression (Scott et al. 2000; Elmquist et al. 2005; Morton et al. 2006). However, LepRs are also widely expressed in numerous extra-hypothalamic regions of the brain, including the hippocampus, cerebellum, amygdala and brain stem (Elmquist et al. 1995). Leptin mRNA, and protein are found with particularly high levels in the thalamus and the Purkinje and granular cell layers of the cerebellum (Morash et al. 1999; Ur et al. 2002) indicating that leptin may be released locally in the brain, acting on specific sensory and motor systems. In human, LepR mRNA is expressed at significantly higher levels in the cerebellum than in the hypothalamus (Elmquist et al. 1998; Mercer et al. 1998). In rodents, LepR expression is also evident in cerebellar neurons (Elmquist et al. 1998; Udagawa et al. 2000) during both embryonic and postnatal stages of development (Elmquist et al. 1998; Udagawa et al. 2006).

Additional functions of this hormone, beyond its role in energy homeostasis, have been identified in the brain. Leptin regulates neuronal firing rates, where some cells are found to be activated while others are inhibited. In particular, there is growing evidence that this hormone markedly influences hippocampal excitatory synaptic transmission as well as hippocampal synaptic plasticity (Shanley et al. 2001). Indeed, Shanley et al. (2002a) demonstrated that leptin has powerful anti-convulsant properties by its ability to significantly reduce hippocampal excitability in two distinct epilepsy models. Electrophysiological studies have shown that leptin hyperpolarizes glucose-responsive NPY/ AGRP (neuropeptide Y-agouti-related protein) neurons via activation of ATP-sensitive $\mathrm{K}^{+}\left(\mathrm{K}_{\mathrm{ATP}}\right)$ channels (Spanswick et al. 1997); this action is likely to result in decreased action potential firing frequency in NPY/AGRP neurons (Takahashi and Cone 2005). The effects of leptin have also been assessed in a penicillin model of epilepsy in the somatomotor cortex. However, in this brain region leptin is reported to have pro-convulsant activity (Ayyildiz et al. 2006), suggesting that there may be regional differences in the capacity of leptin to influence neuronal excitability. A functional link between leptin and cerebellar NMDA (N-methyl-D-aspartate) receptors has been suggested, as leptin-deficient rodents ( $o b / o b$ mice) display deficits in locomotor activity that can be improved by leptin administration (Irving et al. 2006).

It has been shown that transgenic re-introduction of LepR in proopiomelanocortin-positive neurons of $d b / d b$ mice is sufficient to maintain euglycemia, indicating the participation of leptin on regulation of glucose homeostasis (Huo et al. 2009). Symptoms, like loss of pain, impaired touch perception and decreased positional sense, accompanied by structural and neurochemical abnormalities as well as by degenerative changes in the brain, could be related to chronic increase of intracellular glucose concentration (Waxman and Sabin 1981; Hernandez-Fonseca et al. 2009). Although the effects of leptin on brain structures have been observed in the cerebellum, where LepRs are most densely expressed, the function of leptin in the cerebellum remains unclear (Berman et al. 2012). Here, we examined spontaneous action potential firing activity in the soma of Purkinje neurons (PNs) in cerebellar slices of the diabetic mouse $d b / d b$, where the hyperglycemic condition results from alterations in the LepR gene (Berglund et al. 1978). We showed that the $d b / d b$ mutation affects $\mathrm{PN}$ action potential firing in several ways: the proportion of cells that fire spontaneously and that of cells that fire continuously is higher. Also, the firing frequency during active episodes is increased. We also showed that the effects of the $\mathrm{GABA}_{\mathrm{A}}$ receptor blocker bicuculline on firing rate are significantly weaker in $d b / d b$ compared to wild type (WT) PNs, suggesting less GABAergic tonic inhibition in the $d b / d b$ mice an pointing to an additional effect of the $d b / d b$ mutation in neurons (or synapses) upstream of PNs in the cerebellar circuit. Our results also demonstrate that in addition to a weaker tonic GABAergic inhibitory input to $d b / d b$ PNs, the intrinsic firing properties of WT and $d b / d b$ PNs are 
significantly different. The possible origin and functional implications of these alterations are discussed.

\section{Materials and Methods}

\section{Animal model}

Studies were performed under an institutional protocol similar to the USPHS Guide for the Care and Use of Laboratory Animals, and according to the Official Mexican Guide from the Secretary of Agriculture (SAGARPA NOM-062-Z001999), and with the approval of the Ethics Committee of the Institute for Cell Physiology, UNAM. C57BL/6 mice, which carry a spontaneous mutation on the LepR, $(d b / d b)$ mice were used in this study, and their respective WT controls were fed ad libitum and maintained in the Institute's animal facility under constant temperature and $12 \mathrm{~h} / 12 \mathrm{~h}$ light/dark cycle until the day of the experiment. Glucose blood levels were determined every week and on the day of the experiment using the One Touch Basic Plus kit (Johnson \& Johnson Company, CA). (db/db) mice typically had fasting glucose levels above $180 \mathrm{mg} / \mathrm{ml}$. In contrast, WT control mice maintained glucose levels between 90 and $120 \mathrm{mg} / \mathrm{ml}$.

\section{Cerebellar slice preparation}

Mice of 4 to 8 weeks of age were chosen and were anesthetized with ether and decapitated. The cerebellum was rapidly dissected and the cerebellar vermis was isolated after a parasagittal cut. This tissue fragment was submerged in bicarbonate-buffered saline (BBS) containing (in $\mathrm{mM}): 125 \mathrm{NaCl}, 2.5 \mathrm{KCl}, 2 \mathrm{CaCl}_{2}, 1 \mathrm{MgCl}_{2}, 1.25 \mathrm{NaHPO}_{4}$, $26 \mathrm{NaHCO}_{3}$ and glucose $10 \mathrm{mM}$ (290-300 mOsm). BBS was continuously bubbled with $95 \% \mathrm{O}_{2}$ and $5 \% \mathrm{CO}_{2}$ to maintain the $\mathrm{pH}$ at 7.4. To prevent damage caused by temporal hypoxia, the $\mathrm{BBS}$ was kept at $4^{\circ} \mathrm{C}$. The vermis was glued to a teflon stage using cyanoacrilate glue and remained submerged in cold BBS during the slicing procedure. Slices 150 $\mu \mathrm{m}$ thick were obtained using a Series 3000 Plus Vibratome (The Vibratome Company Inc.), and they were transferred to a holding chamber and kept submerged in BBS bubbled with $95 \% \mathrm{O}_{2}$ and $5 \% \mathrm{CO}_{2}$ for one hour at $34^{\circ} \mathrm{C}$. After incubation, slices were transferred to a plexiglas perfusion chamber on the stage of an upright microscope Optiphot 2 (Nikon Corporation Japan), equipped with phase contrast optics and water immersion objectives.

\section{Electrophysiological recordings}

To minimize confounding effects resulting from cell dialysis, electrophysiological recordings were carried out under the cell-attached configuration of the patch clamp technique
(Hamill et al. 1981), which allows recording of electrical activity for many tens of minutes or even hours. Recordings were obtained from the soma of PNs identified by their size and position in the cerebellar cortex. Slices were placed in the recording chamber and perfused $(1-1.5 \mathrm{ml} / \mathrm{min})$ with gassed $\mathrm{BBS}$ at $20-22^{\circ} \mathrm{C}$. Patch pipettes were pulled from borosilicate glass capillaries using a vertical puller Model PP83 (Narashige, Japan). Pipette tip resistance was 8-12 $\mathrm{M} \Omega$ when they were filled with a pipette solution containing (in $\mathrm{mM}$ ): $144 \mathrm{~K}$-gluconate, $6 \mathrm{KCl}, 4.6 \mathrm{MgCl}_{2}$, 10 HEPES, 1 EGTA, $0.1 \mathrm{CaCl}_{2}$; adjusted to a $\mathrm{pH}=7.4$ with $\mathrm{KOH}$ (290-300 mOsm). Spontaneous extracellular action potentials were recorded with a PC-501 amplifier filtered at $1 \mathrm{kHz}$ (Warner Instruments Corp). Data were sampled at $100 \mu \mathrm{s} /$ point with a DigiData 1200 Interface and AxoClamp software, version 8.0 (Axon Instruments, Foster City, CA). Spontaneous extracellular action potentials were recorded (pipette potential $\mathrm{V}_{\mathrm{p}}=0 \mathrm{mV}$ ) from the soma of PNs of WT and $d b / d b$ mice under the continuous acquisition mode of AxoClamp. Only spontaneously active PNs were recorded and used for analysis. Bicuculline ( $30 \mu \mathrm{M}$; Sigma) was used to inhibit the activity of the $\mathrm{GABA}_{\mathrm{A}}$ receptor (type $\mathrm{A} \gamma$ aminobutyric acid receptor-channel).

\section{Analysis of electrophysiological recordings}

Each experiment consisted of 5-20 min continuous recording of spontaneous extracellular action currents resulting from the firing of PN action potentials. During the experiment, the spontaneous action currents (spikes) were recorded continuously onto the PC. The digitized data were analyzed with the pClamp 10.0 software (Molecular Devices). The number of spikes and the inter-spike time interval (ISI) were extracted from the continuous records of spontaneous firing activity with the Event Detection Analysis function of Clamp fit 10 (Threshold-based searches). Event analysis was typically performed on continuous segments of spontaneous action potentials records lasting 3-5 min. The inter-spike interval (ISI) is defined as the time between the onset of the current rise of consecutive events or spikes. In all experiments, the ISI was monitored continuously. The ISI obtained during the $5 \mathrm{~min}$ period immediately prior to pharmacological manipulations was compared to that after 5-15 min of drug exposure. The coefficient of variation (CV) was calculated as described previously (Kullman 1994). Briefly, the mean and SD were calculated for the ISI recorded during successive 3-5 min periods before and during bicuculline treatment $(\mathrm{CV}=$ $\mathrm{SD} /$ mean). Data are expressed as mean \pm SEM. Statistical significance was determined by using either two sample independent or paired tests from the software Origin7 (Microsoft). Differences with $p<0.05$ values were considered statistically significant. 


\section{Results}

Resting firing frequency of spontaneous action potentials is significantly higher in $\mathrm{db} / \mathrm{db}$ mice compared to WT mice

Cerebellar PNs fire with remarkable regularity at high rates even in the absence of excitatory synaptic inputs (Llinas and Sugimori 1980a; Raman and Bean 1999). Both in vitro and in vivo, individual PNs maintain a distinct resting firing rate; some PNs fire as slowly as 5 spikes/s, whereas others fire as rapidly as 80 spikes/s (Hausser and Clark 1997; Raman and Bean 1997). The firing of spontaneous action potentials in cerebellar PNs was examined using long-lasting recordings. PNs from $d b / d b$ mice were spontaneously active more often than PNs from WT mice recorded under the same conditions. Only spontaneously active PNs were considered in this study. Thus, $66.6 \%$ of the PNs from $d b / d b$ mice were spontaneously active, compared to $37 \%$ of neurons in the WT mice (data not shown). Figs. $1 \mathrm{~A}$ and $1 \mathrm{C}$ show representative recordings obtained from WT and $d b / d b$ PNs, respectively. The frequency of spontaneous action potentials was higher

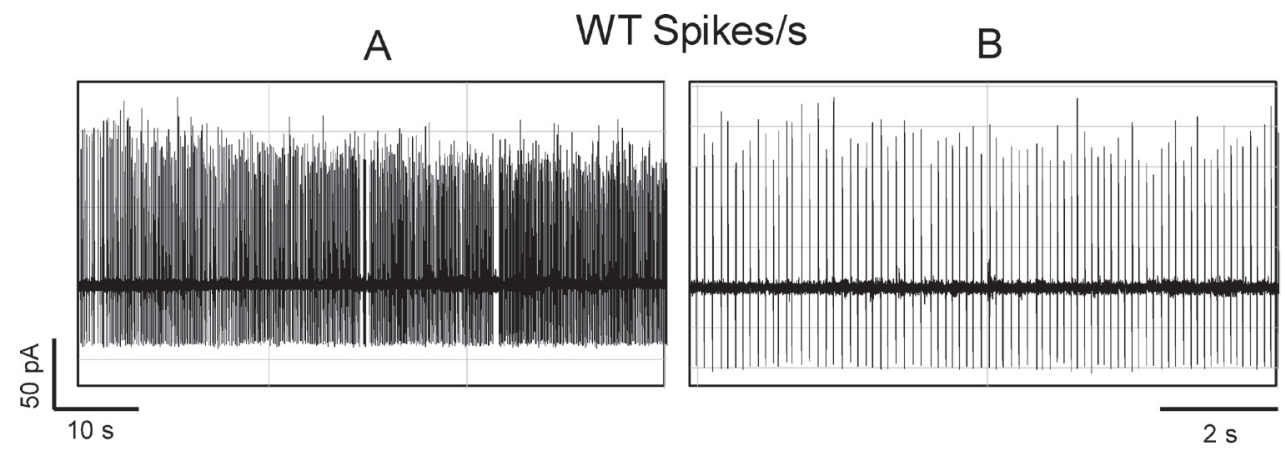

C

$\mathrm{db} / \mathrm{db}$ Spikes/s

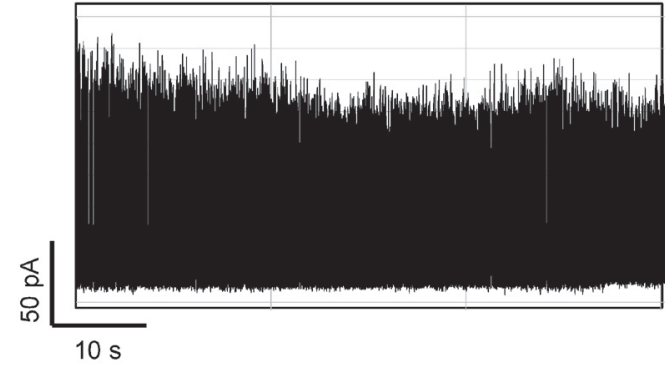

$E$

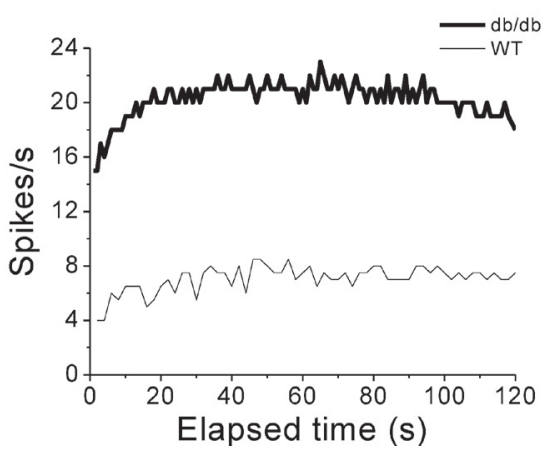

$\mathrm{D}$

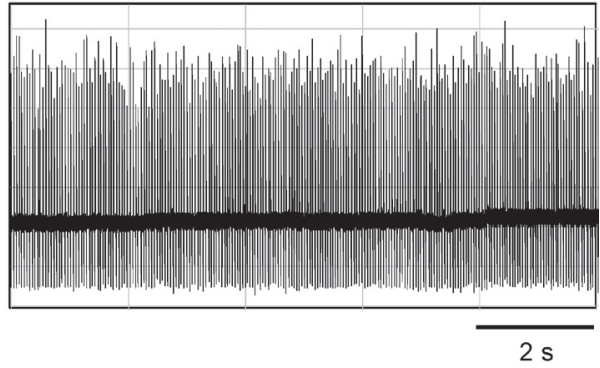

$\mathrm{F}$

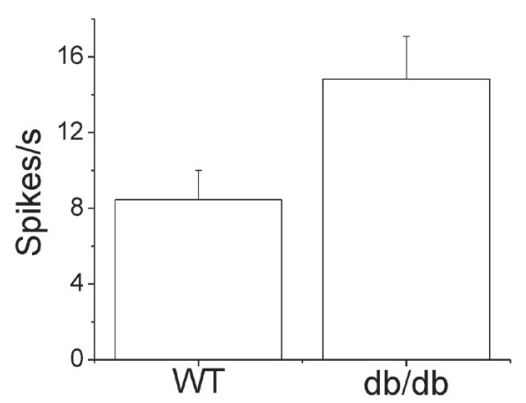

Figure 1. Spontaneous action potential currents recorded from a PNs soma using the cell-attached patch-clamp configuration. Representative recordings of spontaneous action potential currents from a WT Purkinje neuron with different time scale: $50 \mathrm{pA} / 10 \mathrm{~s}(\mathrm{~A})$, $50 \mathrm{pA} / 2 \mathrm{~s}$ (B). C, D. Similar recordings obtained from a PN from $d b / d b$ mice. Recording pipette potential was kept at $0 \mathrm{mV}$. E. Mean firing rate recorded during $120 \mathrm{~s}$ from PNs shown in A and C. F. Mean spike frequency: $8.4 \pm 1.5$ and $14.8 \pm 2.2 \mathrm{spikes} / \mathrm{s}$ for WT and $\mathrm{db} / \mathrm{db} \mathrm{mice}$ PNs, respectively $( \pm \mathrm{SE})$. These mean values are statistically different at the 0.05 level of significance, $(p=0.03 ; n=12)$. 


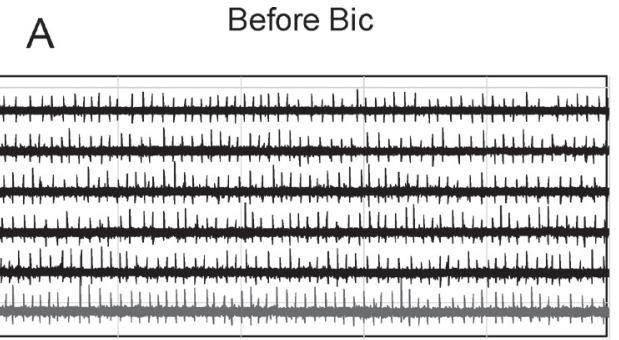

$2 \mathrm{~s}$

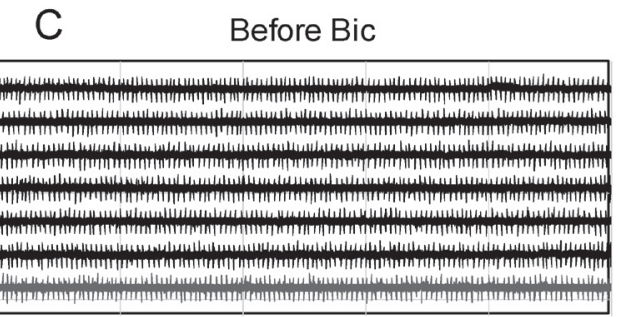

$2 s$

$E$

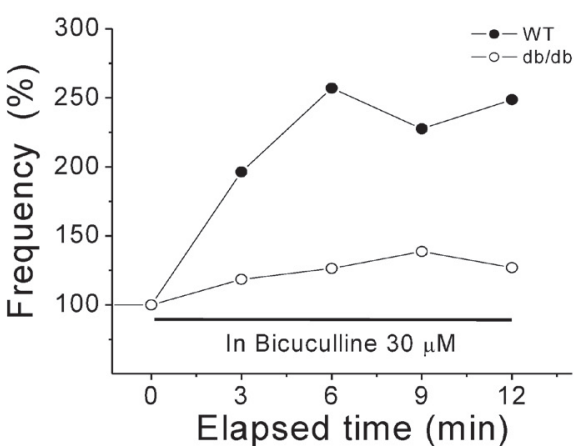

B After Bic

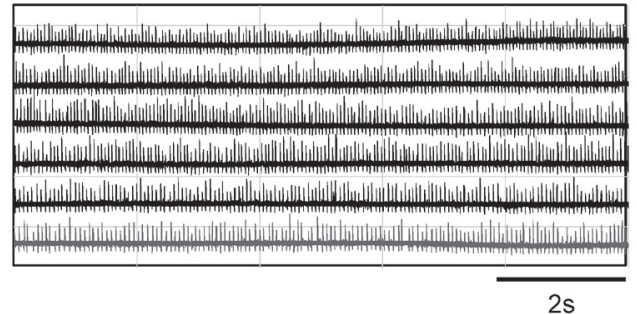

$2 s$

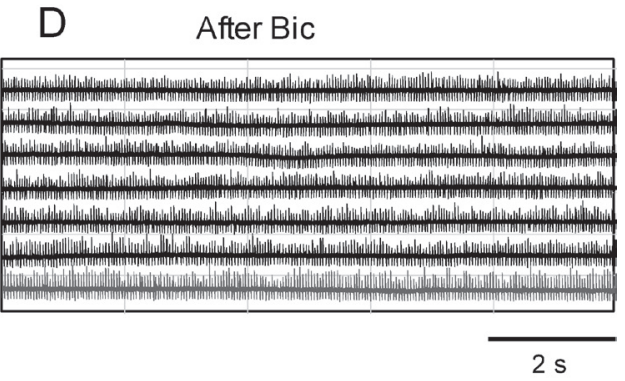

$\mathrm{F}$

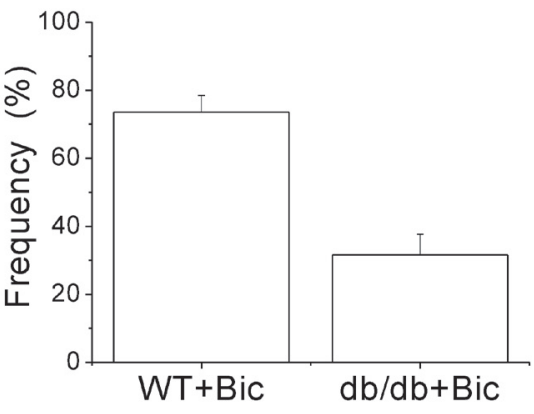

Figure 2. Spontaneous electrical activity of PNs. Effects of the $\mathrm{GABA}_{\mathrm{A}}$ receptor antagonist bicuculline (Bic). Continuous $10 \mathrm{~s}$-long recordings are shown one on top of the other. Inter-spike intervals (ISIs) before (left panel) and after bicuculline application (right panel) from a wild type $(\mathbf{A}, \mathbf{B})$ and a representative $d b / d b \mathrm{PN}(\mathbf{C}, \mathbf{D})$. Notice that firing rate increases in both WT and $d b / d b$ PNs. E. Example traces of percentage frequency values taken at 3,6,9 and 12 min relative to the beginning of bicuculline application from the cells shown in B and D. After a 5 min control period, bicuculline was added at the indicated time. Closed circles: WT PN; open circles: $d b / d b$ PN. F. Average normalized frequency values for the WT and $d b / d b$ Purkinje neurons in the presence of bicuculline.

in $d b / d b$ PNs compared to WT neurons. Figs. $1 \mathrm{~B}$ and $1 \mathrm{D}$ illustrate recordings of spontaneous electrical activity from the PNs shown in $\mathrm{A}$ and $\mathrm{C}$ with an expanded time scale. Fig. 1E compares the spontaneous spike frequency, measured during $120 \mathrm{sec}$, from a WT and a $d b / d b$ PN. The mean resting firing frequency obtained (Fig. $1 \mathrm{~F}$ ) was $8.4 \pm 1.5 \mathrm{~Hz}$ for WT and $14.8 \pm 2.2 \mathrm{~Hz}$ for $d b / d b(n=12)$. At the 0.05 level of significance, averages are statistically different $(p=0.03$ two-sample independent $t$-test).
The increase in firing rate of spontaneous action potentials in the presence of bicuculline is significantly higher in PNs from $W T$ than from $\mathrm{db} / \mathrm{db}$ mice

$\mathrm{GABA}_{\mathrm{A}}$ receptors mediate fast inhibitory synaptic transmission to PNs (Llano et al. 1991; Kano 1996), thus regulating their excitability. The higher firing rate recorded in $d b / d b$ PNs suggests that $\mathrm{GABA}_{\mathrm{A}}$ transmission in PNs could be altered. To monitor intrinsically generated spontaneous 


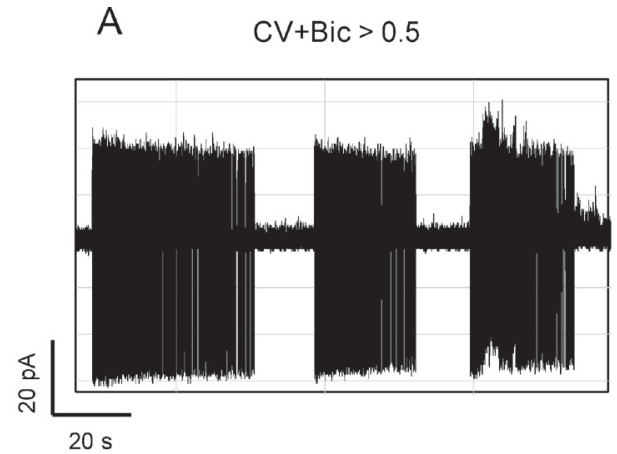

C

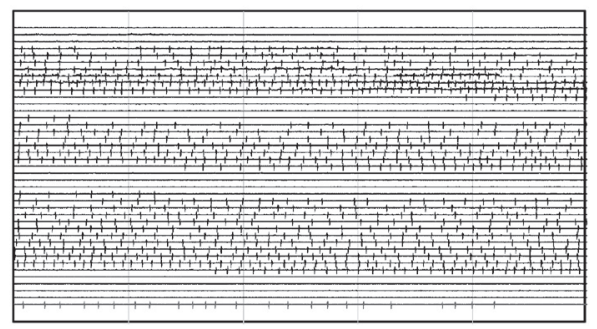

$1 \mathrm{~s}$

E

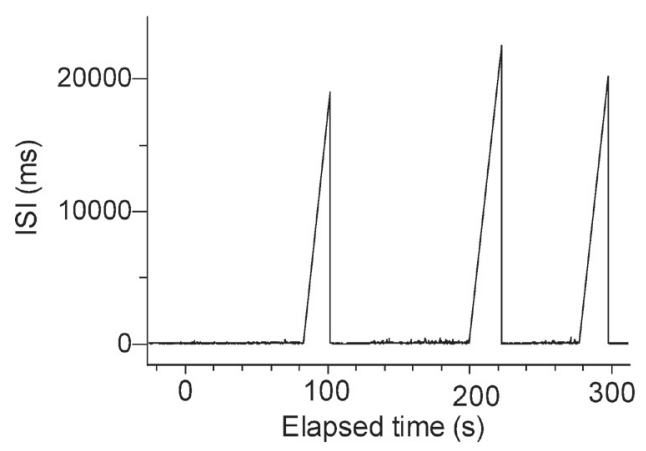

B

$\mathrm{CV}+\mathrm{Bic}<0.5$

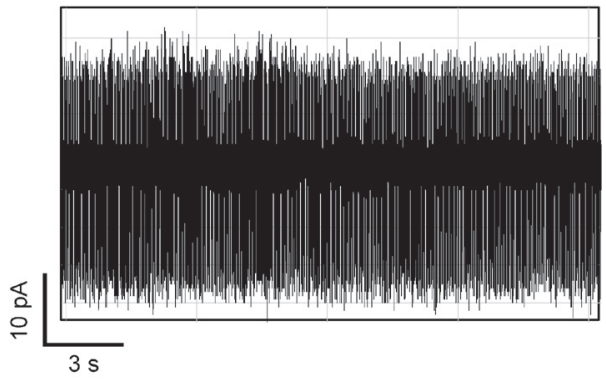

D

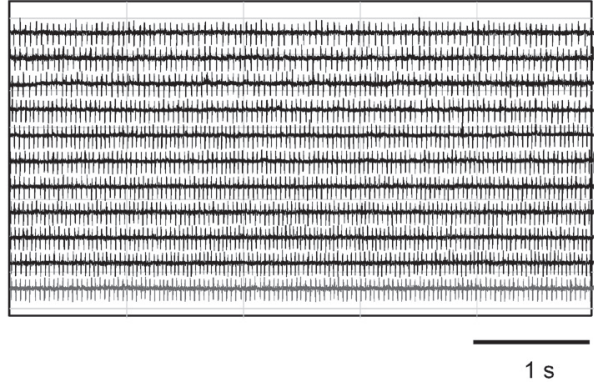

$\mathrm{F}$

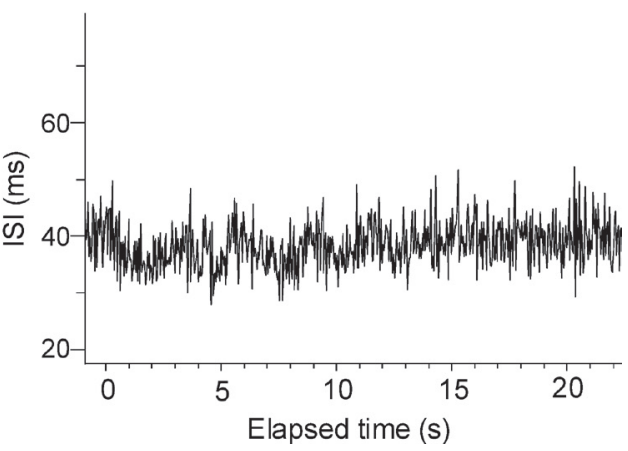

Figure 3. A, B. Representative firing patterns of WT PNs recorded in cell-attached configuration $\left(\mathrm{V}_{\mathrm{p}}=0 \mathrm{mV}\right)$ in the presence of bicuculline (Bic). The coefficient of variation (CV) is shown for each group. C, D. Representative sweeps of action potential recordings (5-s duration) recorded from the PNs shown in A and B, respectively. Note the deep transitions from up to down states when the CV $>0.5$. E, F. Plots of inter-spike interval (ISI) vs. elapsed time for the PNs shown in A and B, respectively.

firing rate and $\mathrm{GABA}_{\mathrm{A}}$ receptor activity, we studied the effects of bicuculline (a potent $\mathrm{GABA}_{\mathrm{A}}$ receptor antagonist at $30 \mu \mathrm{M}$ ), on the spontaneous firing rate of PNs in WT and $d b / d b$ cerebellar slices. Fig. 2 shows the ISIs before (A) and after bicuculline application (B) from a representative WT PN. A similar analysis for a $d b / d b$ PN is shown in Figures $2 \mathrm{C}$ and 2D. Bicuculline increased the baseline firing rate of both $d b / d b$ and WT PNs. In the presence of $30 \mu \mathrm{M}$ bicuculline, the mean spontaneous firing rate increased from $8.0 \pm$ $0.9 \mathrm{~Hz}$ to $13.7 \pm 2.0 \mathrm{~Hz}$ in WT PNs $(n=9)$, and from $14.8 \pm$ $1.9 \mathrm{~Hz}$ to $20.1 \pm 3.5 \mathrm{~Hz}$ in $d b / d b$ PNs $(n=7)$. These values were measured during 12 minute-long recordings. Then, the percentage of change of spontaneous action potential firing rate in the presence of bicuculline was calculated. Fig. 2E shows examples of the frequency value change (percentage of change of the mean frequency during the drug application, relative to the mean basal frequency) both for WT and $d b / d b$ PNs. Data was obtained first in control conditions (5 min) and then at 3,6,9 and $12 \mathrm{~min}$ during the application of $30 \mu \mathrm{M}$ bicuculline. Fig. $2 \mathrm{~F}$ summarizes the mean percentage increase of firing frequency after bicuculline in WT and $d b / d b$ PNs. Mean frequency 

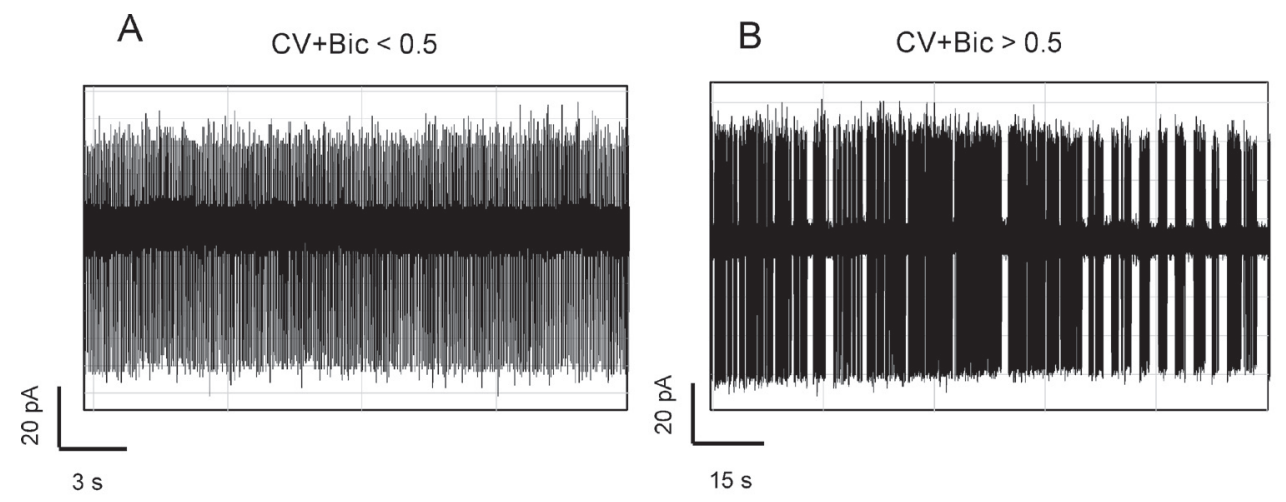

C
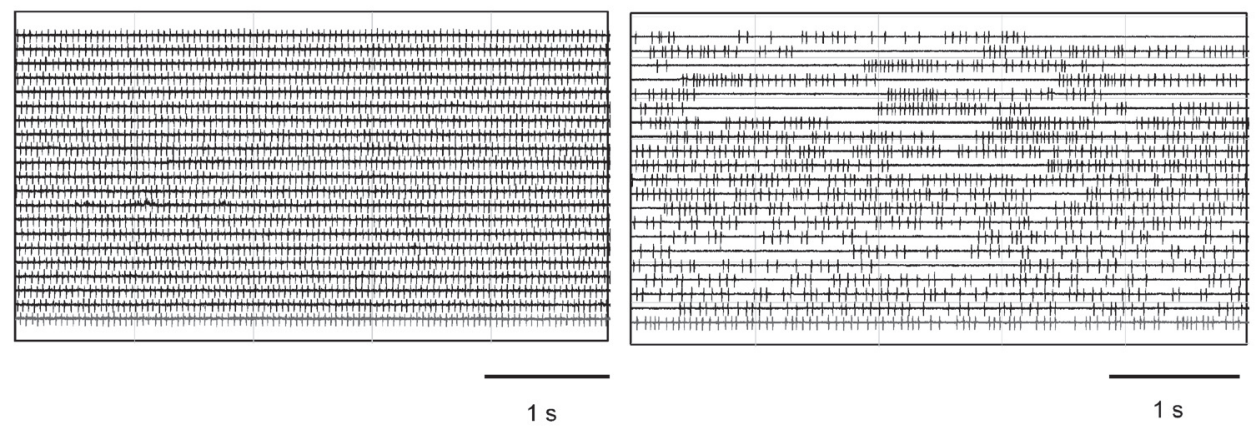

$\mathrm{E}$
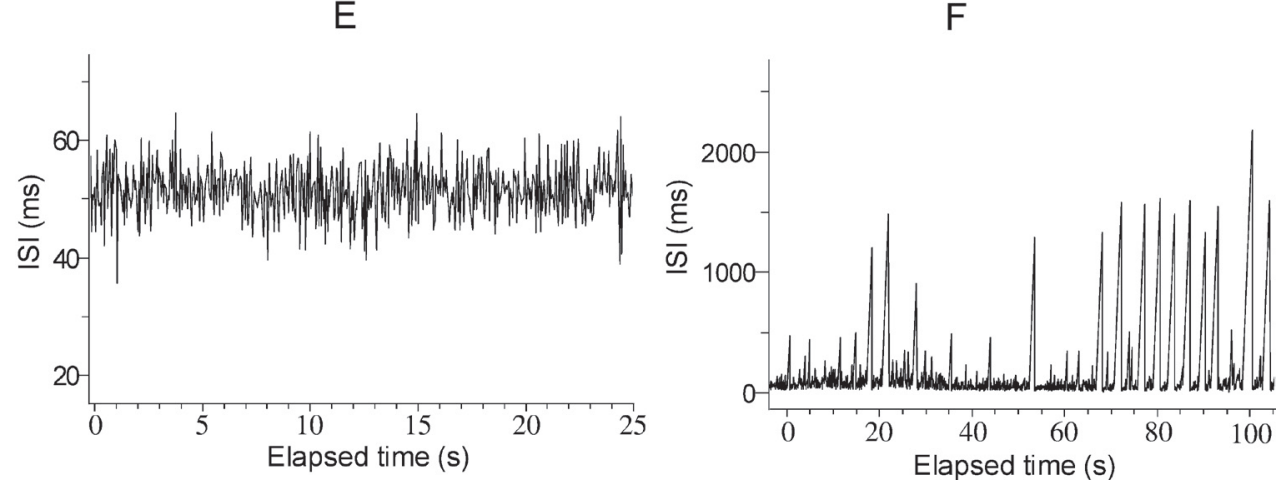

Figure 4. A, B. Representative firing patterns of $d b / d b$ PNs recorded in cell-attached configuration $\left(V_{\mathrm{p}}=0 \mathrm{mV}\right)$ in presence of bicuculline (Bic).The coefficient of variation CV for each group is shown. C, D. Example sweeps of action potential recordings (5-s duration) obtained from the cells shown in A and B, respectively. E, F. Plots of inter-spike interval (ISI) vs. elapsed time from the cells shown in $\mathrm{A}$ and $\mathrm{B}$, respectively.

increased by $73.6 \pm 4.8 \%$, in WT PNs $(n=9)$ and by 31.6 $\pm 6.1 \%$ in $d b / d b$ PNs $(n=7)$ relative to their control firing frequency.

Firing patterns of cerebellar Purkinje neurons from WT mice after bicuculline treatment

The above results suggest that the firing pattern of Purkinje cells is modified in $d b / d b$ mice compared to wild type, both under control conditions and after blocking GABAergic synaptic inputs. So far, we have only considered the firing frequency observed during bursts of action potentials. A potential complication of the analysis is that Purkinje cell firing is complex. While certain cells fire continuously at high rate, in other cases, periods of high frequency firing alternate with silent periods. Therefore a question that arises is whether the $d b / d b$ mutation affects the proportion of continuously firing cells, particularly under conditions where the GABAergic synaptic actions are blocked by bicuculline. Extracellular saline in these experiments contained $30 \mu \mathrm{M}$ 
A

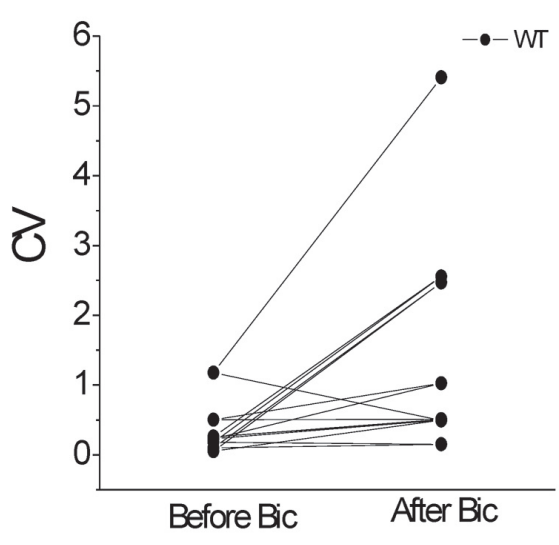

$\mathrm{C}$

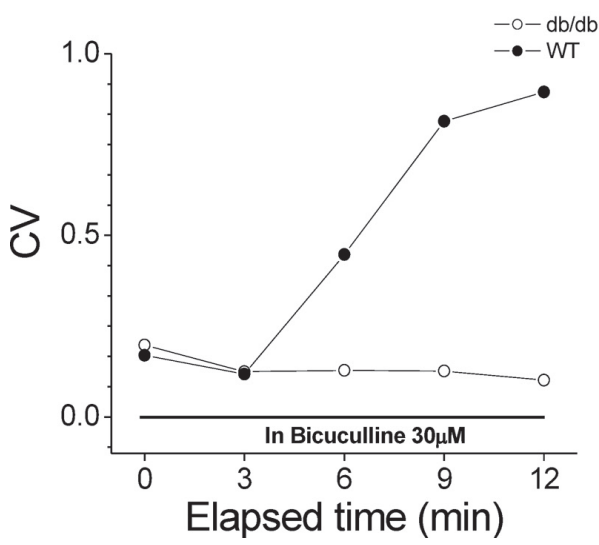

B

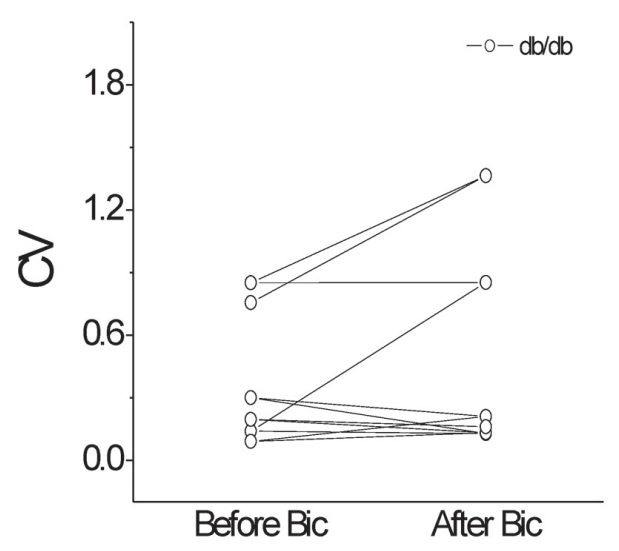

$\mathrm{D}$

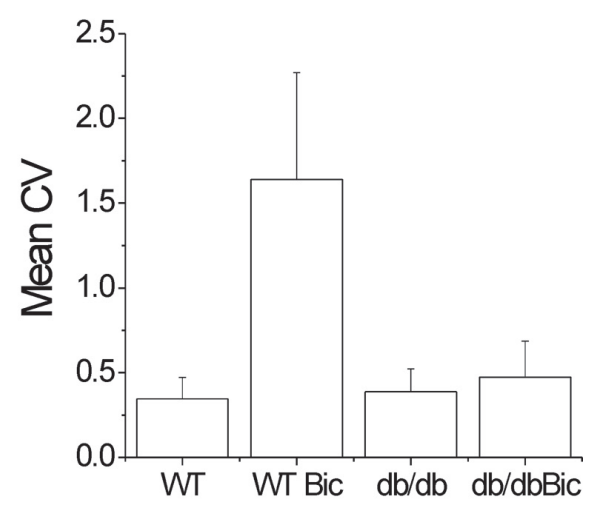

Figure 5. Coefficient of variation (CV) obtained for a set of inter-spike intervals. A. CV obtained for WT PNs before and after bicuculline (Bic) application. Note the differences in CV values in presence of bicuculline. B. Coefficient of variation CV of $d b / d b$ PNs before and after bicuculline application. C. Plot of CV vs elapsed time for representative WT (closed circles) and $d b / d b$ (open circles) PNs. Bicuculline was added at the indicated time. D. Mean CV before and after bicuculline application from WT and $d b / d b$ PNs. Two-sample paired t-test was applied and $p<0.05$ values were accepted as significant.

bicuculline. The observed PN firing pattern was classified in two categories: The first category comprises PNs that fire regularly, without interruption, and with an ISI CV of less than 0.5 ; i.e. cells that display no up-down state changes. The second category comprises PNs that fire regularly, but with relatively long interruptions, and their corresponding mean ISI CV value is greater than 0.5 . These cells show transitions between up and down states, and spontaneous action potentials occur during the up states (Oldfield et al. 2010). Fig. 3 exemplifies recordings from WT mice PNs belonging to the two categories just described. Fig. $3 \mathrm{~A}$ represents a cell whose recording shows up-down state transitions. Presumably bicuculline shifted the discharge patterns from continuous spiking to a burst pattern with quiescent periods between bursts (ISI CV is > 0.5). Fig. 3B corresponds to a PN with continuous, uninterrupted firing. Cells in this category are rare. Figs. 3C and 3D illustrate consecutive $5 \mathrm{~s}$-long recordings of spontaneous electrical activity from the PNs shown in Figs. 3A and 3B, respectively. Silent periods between episodes of continuous, uninterrupted activity are apparent in Fig. 3C. Fig. 3E and 3F are plots of ISI as a function of time, for each of the PNs recordings shown in Figs. 3A 
and $3 \mathrm{~B}$, respectively. The large triangular-shaped peaks in Fig. $3 \mathrm{E}$ correspond to the silent periods (down states), and the flat lines interpolated correspond to the time spent in the up-state (continuous firing; mean frequency $\sim 15 \mathrm{~Hz}$ ). The quiescent periods between bursts, the inter-burst interval (IBI) vary between 0.6 and $20 \mathrm{~s}$ (mean IBI $=6.71 \pm 3.11 \mathrm{~s}$; $n=4$; ISI $\geq 600 \mathrm{~ms}$ ). Seven out of eight PNs recorded in the presence of bicuculline maintained a bursting pattern over time and a high CV value (Oldfield et al. 2010).

Firing patterns of cerebellar Purkinje neurons of $d b / d b$ mice in the presence of bicuculline

Fig. 4 exemplifies representative records of spontaneous action potentials from $d b / d b$ PNs under the same experimental conditions as those described for WT PNs. Similarly to that observed in WT PNs, some $d b / d b$ PNs neurons fire regularly, without interruption (continuous firing pattern) and with an ISI CV of less than 0.5 (Fig. 4A), while other PNs fire regularly, but with interruptions (bursting pattern) and ISI CV values greater than 0.5 (Fig. 4B). Figs. $4 \mathrm{C}$ and $4 \mathrm{D}$ illustrate consecutive recordings, with a faster time scale (5 s per trace), of spontaneous electrical activity from the same $d b / d b$ PNs. Fig. $4 \mathrm{C}$ recording illustrates continuous, uninterrupted electrical activity, while Figure 4D recording shows electrical activity interrupted by many brief, silent periods (bursting pattern). In the presence of bicuculline, four out of seven $d b / d b$ PNs showed regular firing over time and ISI CV values of less than 0.5 (Shin et al. 2007). The remaining 3 PNs displayed bursting pattern, with IBI ranging from 0.5 to $2.0 \mathrm{~s}$ in duration (mean IBI $=2.32 \pm 1.60 \mathrm{~s} ; n=$ 4 ; and ISI $\geq 400 \mathrm{~ms}$ ).

Effects of bicuculline on coefficient of variation of inter-spike intervals in WT and db/db Purkinje neurons

In contrast to the variance of number of spikes counted during repeated experimental observations and thus reflecting variability on a comparably slow time scale of seconds or even minutes, the variance of ISIs reflects intra-trial variability on a relatively fast time scale of tens to hundreds of milliseconds (Fisch 2011). This parameter was used to characterize the spontaneous electrical activity of cerebellar PNs from WT and $d b / d b$ mice (Fig. 5). Fig. 5C compares ISI CV values for both WT (Fig. 5A) and $d b / d b$ PNs (Fig. 5B), before and after bicuculline application. In the presence of bicuculline the ISI CV increased significantly in WT PNs, from $0.34 \pm 0.12$ to $1.64 \pm 0.63(p=0.02 ; n=8)$. In contrast, the ISI CV increased slightly in $d b / d b$ PNs (from $0.38 \pm 0.13$ to $0.47 \pm 0.21)$. This change is not statistically significant $(p=0.45 ; n=6)$. Pooled data is shown in the bar plot of Fig. 5D. These results clearly demonstrate that in addition to the weaker tonic GABAergic inhibitory input to $d b / d b$
PNs, the intrinsic firing properties of WT and $d b / d b$ PNs are significantly different. ISI $=1.64 \pm 0.63$ (WT) versus $0.47 \pm 0.21(d b / d b)$.

\section{Discussion}

Signals for motor coordination and posture maintenance are encoded by the frequency and firing pattern of action potentials in PNs, the only efferent drive from the cerebellar cortex to the deep nuclei (Ito 2001). The firing frequency of these cells is controlled by their intrinsic activity of ion channels responsible for autorhythmicity and by synaptic inputs (Gahwiler and Llano 1989; Raman and Bean 1999). Here we compared the spontaneous firing rate of PNs in cerebellar slices of $d b / d b$ mice (lacking of leptin signaling; leptin resistant mice) and of WT mice. We found that the spontaneous firing rate of $d b / d b$ mice PNs is significantly higher than the WT mice. Recent studies indicate that nitric oxide (NO) released by stimulation of parallel fibers in cerebellar slices diffuses to PNs, where it activates soluble guanylate cyclase (Smith and Otis 2003) which results in a rise in guanosine 3', 5'-cyclic monophosphate (cGMP). This cGMP rise stimulates cGMP-dependent protein kinase $(\mathrm{PKG})$ and increases firing rate, presumably by phosphorylation of target proteins i.e. ion channels (Häusser et al. 2004; Grieco et al. 2002). On the other hand, electrophysiological studies of monoamine-derived aldehydes on single neurons in rat neocortex and cerebellum concluded that serotonin and 5-hydroxy-3-acetaldehyde caused pronounced depression of firing rates of cerebellar PNs and neurons of the prefrontal cortex (Palmer et al. 1986). Leptin effects on neuronal excitability have been associated to the modulation of NO synthase activity, brain serotonin (5-HT) metabolism and the activity of potassium channels: Intra-cerebroventricular (ICV) leptin injections inhibit diencephalic NO synthase activity and increases brain serotonin metabolism in mice (Calapai et al. 1999), which could explain a serotonin-dependent mechanism of leptin regulation of appetite, and energy consumption (Yadav et al. 2011). Studies on hippocampal neurons have shown that leptin decreases neuronal excitability through a PI3-kinase-driven signaling cascade that activates large conductance $\mathrm{Ca}^{2+}$-activated $\mathrm{K}^{+}$channels (Shanley et al. 2002a). Current efforts are being focused on identifying the contribution of several candidate ionic channels to the modulation of firing rate, particularly $\mathrm{Ca}^{2+}$-activated $\mathrm{K}^{+}$ currents (Womack and Khodakhah 2002) and resurgent $\mathrm{Na}^{+}$currents (Grieco et al. 2002; Raman and Bean 2001; Khaliq et al. 2003). Since the LepR mRNA is abundant in Purkinje and granule cell layers of the cerebellum (Elmquist et al. 1998), it is conceivable that the hyper-excitability of cerebellar PNs observed in the $d b / d b$ mice is due in part 
to the inability of leptin to activate BK channels, or to inhibit the NO synthase activity and increase the serotonin metabolism.

The electrical activity of PNs is also regulated by the neuronal network within the cerebellar cortex, which exerts its inhibitory effects through GABA release from interneurons. During tonic GABAergic inhibition, GABA present in the extracellular space activates $\mathrm{GABA}_{\mathrm{A}}$ ionotropic receptors of PNs. This inhibition can be suppressed by the $\mathrm{GABA}_{\mathrm{A}}$ receptor blocker bicuculline (Bormann 2000; Richerson 2004). Here we found evidence that in leptin-deficient $d b / d b$ mice, tonic GABAergic inhibition of cerebellar PNs is diminished compared to that of WT mice.

The content of cGMP in PNs is affected not only by the activity of climbing and mossy fibers but also by the activation of $\mathrm{GABA}_{\mathrm{A}}$ receptors: intracellular [cGMP] decreases when PNs are inhibited, and conversely, intracellular [cGMP] increases when they are excited (Biggio et al. 1997). Climbing fiber-evoked $\mathrm{PN}$ discharge reduces the expression of $\mathrm{GABA}_{\mathrm{A}}$ receptor-associated protein and decreases its interaction with $\mathrm{GABA}_{\mathrm{A}}$ receptors, rendering $\mathrm{PNs}$ less susceptible to interneuronal GABAergic inhibition (Qian et al. 2011). The fact that a decrease of GABAergic transmission increases [cGMP] suggests the activation of the NO signaling cascade in the cerebellum, which has been associated with an increased firing rate of PNs and with the regulation of ingestive behavior, since the inhibitors of NO synthase activity produce anorectic effects and reduce body weight gain (Calapai et al. 1999). Recent studies on cerebellar GAD and $\mathrm{GABA}_{\mathrm{A}}$ receptors in hypoglycemic and diabetic mice, showed evidence for a decrease of total GABA receptor binding and glutamic acid decarboxylase mRNA expression compared to control mice. This presumably decreases the GABAergic functional regulation in the cerebellum (Shalman 2010). Although a selective loss of tonic inhibition is expected to promote seizures, there is no direct evidence for a link between decreased tonic inhibition, seizures and leptin signaling in the cerebellum. However, more sophisticated forms of modulation could also be important: Rather than simply decreasing the number of action potentials generated by PNs, tonic inhibition can also affect the neuronal firing patterns (Hausser and Clark 1997). Changes in such firing pattern could imply a more subtle role of GABAergic tonic inhibition in information processing and not only in the control of overall brain excitability. Our results show that blockade of GABAergic tonic inhibition by bicuculline modifies the firing pattern from continuous, uninterrupted spiking into burst firing. In addition, bicuculline increases the length of quiescent periods and the intra-burst firing rate in WT but not in $d b / d b$ PNs. The appearance of burst firing has been related to an accelerated activation of an inwardly directed cationic current and a depression of the spike after-hyperpolarization (Antkowiak and Heckj 1997).
Electrophysiological studies in PN somata suggest that the slow membrane potential fluctuations that regulate the overall duration of the burst of action potentials (10-15 s) are $\mathrm{Ca}^{2+}$-dependent. In the absence of extracellular $\mathrm{Ca}^{2+}$ the auto-rhythmicity of these cells ceases, since autonomous firing is probably modulated by stimulation of both $\mathrm{Ca}^{2+}$ and cGMP-mediated protein phosphorylation (Greengard 1978; Llinas and Sugimori 1980a). A detailed electrophysiological analysis of amplitude and frequency of postsynaptic inhibitory currents (IPSCs) on PN soma (Kano 1996) is required to confirm if GABAergic synaptic transmission is reduced in $d b / d b$ mice, and to determine if these effects can be attributed to pre- or postsynaptic mechanisms. Additionally, it will be important to clarify if the increased excitability of cerebellar PNs in $d b / d b$ mice results from hyperglycemia or from the lack of leptin signaling, since both conditions coexist in this mouse strain.

\section{Conclusions}

Signals for motor coordination and posture maintenance are encoded by the frequency and firing pattern of action potentials in cerebellar PNs, the only output from the cerebellar cortex to the deep nuclei. PN firing is highly complex; some cells are silent while others are active; in some active cells, periodic firing alternates with silent periods, for reasons which are only partially understood, while other active cells fire continuously. The spontaneous firing frequency of PNs mainly originates from the activity of ion channels responsible for auto-rhythmicity and is modulated by synaptic inputs. Spontaneous action potential generation in PNs from $d b / d b$ mice (lacking of leptin signaling) take place at a significantly higher rate compared to WT mice. Bicuculline (a potent $\mathrm{GABA}_{\mathrm{A}}$ receptor antagonist), is less efficient to increase spontaneous action potential firing and modifying firing patterns in cerebellar PNs from $d b / d b$ mice compared to WT mice, suggesting weaker GABAergic tonic inhibition on these cells and implicating additional effects of the $d b / d b$ mutation in neurons (or synapses) upstream of PNs in the cerebellar circuit. Our results also showed that the intrinsic firing properties (auto-rhythmicity) of $\mathrm{WT}$ and $d b / d b$ PNs are significantly different. It remains to be elucidated if the increased excitability of cerebellar PNs in $d b / d b$ mice results from hyperglycemia or from the lack of leptin signaling, since both conditions coexist in this mouse strain.

Acknowledgements. Supported by grants IN222413 (DGAPAUNAM) PICSA10-116 (ICyTDF; Instituto de Ciencia y Tecnología del DF) and 039-2013 SECITI (Secretaría de Ciencia, Tecnología e Innovación del DF). M. E. Forero-Vivas received a Ph. D. Fel- 
lowship from DGAPA-UNAM; and additional support from the $\mathrm{Ph}$. D. Program in Biomedical Sciences (UNAM). The authors are indebted to Drs. Marcia Hiriart, José Bargas, Enrico Nasi, María del Pilar Gómez, Isabel Llano and Alain Marty, who provided invaluable insights. We also are grateful to Nicolas Jiménez and Diana Millán for expert technical assistance and to Claudia V. Rivera for continuous advice. This study was performed by M. E. Forero-Vivas as partial fulfillment of the requirements to obtain the Ph. D. in Biomedical Sciences (UNAM).

\section{References}

Antkowiak B., Heckj D. (1997): Effects of the volatile anesthetic Enflurane on spontaneous discharge rate and GABAA-mediated inhibition of Purkinje cells in rat cerebellar slices. Neurophysiology 77, 2525-2538

Ayyildiz M., Yildirim M., Agar E., Baltaci A. K. (2006): The effect of leptin on penicillin-induced epileptiform activity in rats. Brain. Res. Bull. 68, 374-378 http://dx.doi.org/10.1016/j.brainresbull.2005.09.012

Banks W. A. (2006): Blood-brain barrier and energy balance. Obesity (Silver Spring) 14, S234-237 http://dx.doi.org/10.1038/oby.2006.315

Banks W. A., Farrell C. L. (2003): Impaired transport of leptin across the blood-brain barrier in obesity is acquired and reversible. Am. J. Physiol. Endocrinol. Metab. 285, E10-15

Berglund O., Frankel B. J., Hellman B. (1978.) : Development of insulin secretory defect in the geneticaly diabetic $(\mathrm{db} / \mathrm{db})$ mouse. Acta Endocrinol. 87, 543-545

Berman S. M., Paz-Filho G., Wong M. L., Kohno M., Licinio J., Edythe D. (2013): Effects of leptin deficiency and replacement on cerebellar response to food-related cues. Cerebellum 12, $59-67$ http://dx.doi.org/10.1007/s12311-012-0360-z

Biggio G., Brodie B. B., Costa E., Guidotti A. (1977): Mechanisms by which diazepam, muscimol, and other drugs change the content of cGMP in cerebellar cortex. Proc. Natl. Acad. Sci. U.S.A. 74, 3592-3596 http://dx.doi.org/10.1073/pnas.74.8.3592

Bjørbæck C., Uotani S., da Silva B., Flier J. S. (1997): Divergent signaling capacities of the long and short isoforms of the leptin receptor. J. Biol. Chem. 272, 32686-32695 http://dx.doi.org/10.1074/jbc.272.51.32686

Bjørbaek C., Kahn B. B. (2004) : Leptin signaling in the central nervous system and the periphery. Recent Prog. Horm. Res. 59, 305-331 http://dx.doi.org/10.1210/rp.59.1.305

Bormann J. (2000): The "ABC" of GABA receptors. Trends Pharmacol. Sci. 21, 16-19 http://dx.doi.org/10.1016/S0165-6147(99)01413-3

Calapai G., Corica F., Corsonello A., Sautebin L., Di Rosa M., Campo G.M., Buemi M., Mauro V. N., Caputi A. P. (1999): Leptin increases serotonin turnover by inhibition of brain nitric oxide synthesis. J. Clin. Invest. 104, 975-982 http://dx.doi.org/10.1172/JCI5867

Campfield L. A., Smith F. J., Guisez Y., Devos R., Burn P. (1995): Recombinant mouse OB protein: evidence for peripheral signal linking adiposity and central neural networks. Science 269, 546-549

http://dx.doi.org/10.1126/science.7624778

Coleman D. L. (1978): Obesity and diabetes: two mutant genes causing diabetes-obesity syndrome in mice. Diabetologia 14, $141-148$ http://dx.doi.org/10.1007/BF00429772

Elmquist J. K., Bjørbæk C., Ahima R. S., Flier J. S., Saper C. B. (1998): Distributions of leptin receptor mRNA isoforms in the rat brain. J. Comp. Neurol. 395, 535-547

h t t p: / / dx.doi.org/ 10.1002 / ( S I C I ) 1096 9861(19980615)395:4<535::AID-CNE9>3.0.CO;2-2

Elmquist J. K., Coppari R., Balthasar N., Ichinose M., Lowell B. B. (2005): Identifying hypothalamic pathways controlling food intake, body weight, and glucose homeostasis. J. Comp. Neurol. 493, 63-71 http://dx.doi.org/10.1002/cne.20786

Elmquist J. K., Elias C. F., Saper C. B. (1999): From lesions to leptin: hypothalamic control of food intake and body weight. Neuron 22, 221-232 http://dx.doi.org/10.1016/S0896-6273(00)81084-3

Fisch K. (2011): The contribution of spike-frequency adaptation to the variability of spike responses in a sensory neuron. Dissertationan der Fakultät für Biologie der Ludwig-MaximiliansUniversität München vorgelegt von München. Ed. LudwigMaximilians-Universität München. München

Friedman J. M., Halaas J. L. (1998): Leptin and the regulation of body weight in mammals. Nature $395,763-770$ http://dx.doi.org/10.1038/27376

Gahwiler B. H., Llano I. (1989): Sodium and potassium conductances in somatic membranes of rat Purkinje cells from organotypic cerebellar cultures. J. Physiol. 417, 105-122

Greengard P. (1978): Phosphorylated proteins as physiological effectors. Science 199, 146-152 http://dx.doi.org/10.1126/science.22932

Grieco T. M., Afshari F. S., Raman I. M. (2002): A role for phosphorylation in the maintenance of resurgent sodium current in cerebellar Purkinje neurons. J. Neurosc. 22, 3100-3107

Hamill O. P., Marty A., Neher E., Sakmann B., Sigworth F. J. (1981): Improved patch-clamp techniques for high-resolution current recording from cells and cell free patches. Pflüg. Arch. Eur. J. Phy. 391, 85-100 http://dx.doi.org/10.1007/BF00656997

Hausser M., Clark B. A. (1997): Tonic synaptic inhibition modulates neuronal output pattern and spatiotemporal synaptic integration. Neuron 19, 665-678 http://dx.doi.org/10.1016/S0896-6273(00)80379-7

Häusser M., Raman I. M., Otis T. S., Smith S. L., Nelson A., du Lac S. (2004): Annual meeting mini-symposium the beat goes on: spontaneous firing in mammalian neuronal microcircuits. J. Neurosci. 24, 9215-9219 http://dx.doi.org/10.1523/JNEUROSCI.3375-04.2004

Hernandez-Fonseca J. P., Rincon J., Pedreanez A., Viera N., Arcaya J. L., Carrizo E., Mosquera J. (2009): Structural and ultrastructural analysis of cerebral cortex, cerebellum, and hypothalamus from diabetic rats. Exp. Diabetes Res. 2009, 329632 http://dx.doi.org/10.1155/2009/329632 
Huo L., Gamber K., Greeley S., Silva J., Huntoon N., Leng X. H., Bjørbaek C. (2009): Leptin-dependent control of glucose balance and locomotor activity by POMC neurons. Cell Metab. 9, 537-457 http://dx.doi.org/10.1016/j.cmet.2009.05.003

Irving A. J., Wallace L., Durakoglugil D., Harvey J. (2006): Leptin enhances NR2B-mediated NMDA responses via a MAPKdependent process in cerebellar granule cells. Neuroscience 138, $1137-1148$ http://dx.doi.org/10.1016/j.neuroscience.2005.11.042

Ito M. (2001): Cerebellar long-term depression: Characterization, signal transduction, and functional roles. Physiol. Rev. 81, 1143-1195

Kano M. (1996): Long-lasting potentiation of GABAergic inhibitory synaptic transmission in cerebellar Purkinje cells: Its properties and possible mechanisms. Behav. Brain Sci. 19, 354-361 http://dx.doi.org/10.1017/S0140525X00081450

Khaliq Z. M., Gouwens N. W., Raman I. M. (2003): The contribution of resurgent sodium current to high-frequency firing in Purkinje neurons: an experimental and modeling study. J. Neurosci. 23, 4899-4912

Kullmann D. M. (1994): Amplitude fluctuations of dual component EPSCs in hippocampal pyramidal cells: implications for longterm potentiation. Neuron 12, 1111-1120 http://dx.doi.org/10.1016/0896-6273(94)90318-2

Llano I., Leresche N., Marty A. (1991): Calcium entry increases the sensitivity of cerebellar Purkinje cells to applied GABA and decreases inhibitory synaptic currents. Neuron 6, 565-574 http://dx.doi.org/10.1016/0896-6273(91)90059-9

Llinas R., Sugimori M. (1980a): Electrophysiological properties of in vitro Purkinje cell somata in mammalian cerebellar slices. J. Physiol. 305, 171-195

Matson C. A., Reid D. F., Cannon T. A., Ritter R. C. (2000): Cholecystokinin and leptin act synergistically to reduce body weight. Am. J. Physiol-Reg. I. 278, R882-890

Mercer J. G., Moar K. M., Hoggard N. (1998): Localization of leptin receptor $(\mathrm{Ob}-\mathrm{R})$ messenger ribonucleic acid in the rodent hindbrain. Endocrinology 139, 29-34 http://dx.doi.org/10.1210/en.139.1.29

Morash B, Li S. A., Murphy P. R., Wilkinson M., Ur E. (1999): Leptin gene expression in the brain and pituitary gland. Endocrinology 140, 5995-5998

http://dx.doi.org/10.1210/en.140.12.5995

Morton G. J., Cummings D. E., Baskin D. G., Barsh G. S., Schwartz M. W. (2006): Central nervous system control of food intake and body weight. Nature 443, 289-295 http://dx.doi.org/10.1038/nature05026

Niswender K. D., Morton G. J., Stearns W.H., Rhodes C. J., Myers M. G. Jr., Schwartz M. W. (2001): Intracellular signalling. Key enzyme in leptin-induced anorexia. Nature 413, 794-795 http://dx.doi.org/10.1038/35101657

Oldfield C. S., Marty A., Stell B. M. (2010) : Interneurons of the cerebellar cortex toggle Purkinje cells between up and down states. Proc. Natl. Acad. Sci. U S A. 107, 13153-13158 http://dx.doi.org/10.1073/pnas.1002082107

Palmer M. R., Tottmar O., Deitrich R. A. (1986) : Electrophysiological effects of monoamine-derived aldehydes on single neurons in neocortex and cerebellum in rats. Alcohol. Clin. Exp. Res. 10, 682-685 http://dx.doi.org/10.1111/j.1530-0277.1986.tb05168.x

Qian Z., Yakhnitsa V., Barmack N. H. (2011): Climbing fiber-evoked Purkinje cell discharge reduces expression of GABAa receptorassociated protein and decreases its interation with GABAa receptors. J. Neurochem. 117, 197-208 http://dx.doi.org/10.1111/j.1471-4159.2010.07119.x

Raman I. M., Bean B. P. (1999): Ionic currents underlying spontaneous action potentials in isolated cerebellar Purkinje neurons. J. Neurosci. 19, 1663-1674

Raman I. M., Bean B. P. (2001): Inactivation and recovery of sodium currents in cerebellar Purkinje neurons: evidence for two mechanisms. Biophys. J. 80, $729-737$ http://dx.doi.org/10.1016/S0006-3495(01)76052-3

Raman I. M., Bean B. P. (1997): Resurgent sodium current and action potential formation in dissociated cerebellar Purkinje neurons. J. Neurosci. 17, 4517-4526

Richerson G. B. (2004): Looking for GABA in all the wrong places: the relevance of extrasynaptic GABAA receptors to epilepsy. Epilepsy Curr. 4, 239-242 http://dx.doi.org/10.1111/j.1535-7597.2004.46008.x

Robertson S. A., Leinninger G. M., Myers M. G. Jr. (2008) : Molecular and neural mediators of leptin action. Physiol. Behav. 94, 637-642 http://dx.doi.org/10.1016/j.physbeh.2008.04.005

Schwartz M. W., Peskind E., Raskind M., Boyko E. J., Porte D Jr. (1996): Cerebrospinal fluid leptin levels: Relationship to plasma levels and to adiposity in humans. Nat. Med. 2, 589-593 http://dx.doi.org/10.1038/nm0596-589

Shafrir E. (1992): Animal models of non insulin dependent diabetes. Diabetes Metab. Rev. 8, 179-208 http://dx.doi.org/10.1002/dmr.5610080302

Shalman A. (2010): Muscarinic M1, M3, nicotinic, GABAA and $\mathrm{GABAB}$ receptor subtypes gene expression in insulin induced hypoglycemic rat brain regions: functional regulation through phospholipase $\mathrm{C}$ and creb protein. $\mathrm{PhD}$ Thesis. Cochin University of Science and Technology. Cochin, India

Shanley L. J., Irving A. J., Harvey J. (2001): Leptin enhances NMDA receptor function and modulates hippocampal synaptic plasticity. J. Neurosci. 21, RC186

Shanley L. J., Irving A. J., Rae M. G., Ashford M. L., Harvey J. (2002a): Leptin inhibits rat hippocampal neurons via activation of large conductance calcium-activated K+ channels. Nat. Neurosci. 5, 299-300 http://dx.doi.org/10.1038/nn824

Shanley L. J., O'Malley D., Irving A. J., Ashford M. L., Harvey J. (2002b): Leptin inhibits epileptiform-like activity in rat hippocampal neurones via PI 3-kinase-driven activation of BK channels. J. Physiol. 545, 933-944 http://dx.doi.org/10.1113/jphysiol.2002.029488

Shin S. L., Hoebeek F. E., Schonewille M., De Zeeuw C. I., Aertsen A., De Schutter E. (2007): Regular patterns in cerebellar purkinje cell simple spike trains. PLoS One 2, e485 http://dx.doi.org/10.1371/journal.pone.0000485

Smith S. L., Otis T. S. (2003): Persistent changes in spontaneous firing of Purkinje neurons triggered by the nitric oxide signaling cascade. J. Neurosci. 23, 367-372 
Spanswick D., Smith M. A., Groppi V.E., Logan S. D., Ashford M. L. (1997): Leptin inhibits hypothalamic neurons by activation of ATP-sensitive potassium channels. Nature 390, 521-525

http://dx.doi.org/10.1038/37379

Srinivasan K., Ramarao P. (2007): Animal models in type 2 diabetes research: An overview. Indian J. Med. Res-B. 125, 451-472

Takahashi K. A., Cone R. D. (2005): Fasting induces a large, leptindependent increase in the intrinsic action potential frequency of orexigenic arcuate nucleus neuropeptide Y/Agouti-related protein neurons. Endocrinology 146, 1043-1047 http://dx.doi.org/10.1210/en.2004-1397

Tartaglia L. A., Dembski M., Weng X., Deng N., Culpepper J., Devos R., Richards G. J., Campfield L. A., Clark F. T., Deeds J. et al. (1995): Identification and expression cloning of a leptin receptor. Cell 83, 1263-1271 http://dx.doi.org/10.1016/0092-8674(95)90151-5

Udagawa J., Hashimoto R., Hioki K., Otani H. (2006): The role of leptin inthe development of the cortical neuron in mouse embryos. Brain Res. 1120, 74-82

http://dx.doi.org/10.1016/j.brainres.2006.08.116
Udagawa J., Hatta T., Naora H., Otani H. (2000): Expression of the long form of leptin receptor $(\mathrm{Ob}-\mathrm{Rb}) \mathrm{mRNA}$ in the brain of mouse embryos and newborn mice. Brain Res. 868, 251-258 http://dx.doi.org/10.1016/S0006-8993(00)02334-9

Ur E., Wilkinson D. A., Morash B. A., Wilkinson M. (2002): Leptin immunoreactivity is localized to neurons in rat brain. Neuroendocrinology $75,264-272$ http://dx.doi.org/10.1159/000054718

Waxman S. G., Sabin T. D. (1981): Diabetic truncal polyneuropathy. Arch. Neurol. 38, 46-47 http://dx.doi.org/10.1001/archneur.1981.00510010072013

Womack M., Khodakhah K. (2002): Active contribution of dendrites to the tonic and trimodal patterns of activity in cerebellar Purkinje neurons. J. Neurosci. 22, 10603-10612

Yadav V. K., Oury F., Tanaka K., Thomas T., Wang Y., Cremers S., Hen R., Krust A., Chambon P., Karsenty G. (2011): Leptin-dependent serotonin control of appetite: temporal specificity, transcriptional regulation, and therapeutic implications. J. Exp. Med. 208, 41-52 http://dx.doi.org/10.1084/jem.20101940

Received: February 7, 2013

Final version accepted: June 13, 2013 